\title{
The Effects of Sandplay Therapy on Internalized Shame and Self-expression of Children of Alcoholics
}

\author{
$\mathrm{Na}$, Gyoung hee*
}

\author{
Mikyung Jang**
}

\begin{abstract}
$<$ Abstract $>$
The study investigated how the sand play therapy reduces the internalized shame, which the children of alcoholics would have inside, but improves the children's self-expression. The children of alcoholics are understood to feel several emotions as anxiety, depression, low self-esteem, shame and anger. They generally try not to expose their problems caused by alcohol and other dysfunctions of their families as they either go silent with those problems or pretend that they do not have the problems at all from the beginning. Because of that, however, the children of alcoholics come to have a hard time with building up close relationships with others. In that regard, the study looked into how the sand play therapy could reduce the internalized shame of those children of alcoholics but improve their self-expression which would eventually help the children to be healthy both psychologically and socially. What the study has learned during the therapy is summarized as follows. First, the sand play therapy turned out to be efficient in reducing the internalized shame of the children of alcoholics. Second, the sand play therapy improved the self-expression of the children of alcoholics.
\end{abstract}

Keywords : sandplay therapy, internalized shame, self-expression, children of alcoholics

* Play therapist, Gonggam Play and Development Center (gyoungheena@gmail.com)

** Professor, Department of Child Welfare at Namseoul University (jangmiky@hotmail.com) 
Journal of Symbols \& Sandplay Therapy, Vol.8 No.1.

\section{Introduction}

\section{Research Necessity and Objective}

Characterized by chronicity and recurrence, alcoholism is one of the major mental health concerns for adults. Bringing about not only physical, mental and social problems to the alcoholics but also negative effects to the entire family, alcoholism is considered as not an individual's disease but a family disease. Family members are not separated from each other; they are influenced by the relationships of its constituent members (Park, Lee \& Jeh, 2001).

Children of alcoholics (COAs) are the most vulnerable family members to the devastating effects of alcoholism. COAs are exposed to domestic violence, including physical, verbal and sexual abuse. These children have a poor self-esteem and feel guilty that they are the cause of parental alcoholism. They also suffer from tension, anxiety and depression, which are largely attributable to the unexpected behavior on the part of the parents (Sohn, 1993). Lowered self-esteem caused by shame, guilt, frustration, and other types of negative emotions largely influence their mental health (Min, 2000; Lee, 1995; Hwang, 1998; Green, 2001; Workman \& Beer, 1992). Plus, COAs often tend to hide the problem of alcoholism in the family. They therefore have difficulty in establishing relationships, and their repressed emotions are often manifested as aggression, hence disrupting their inter-personal relationships and social life (Choi, 1996).

The lack of proper role models in the family leads COAs to develop a weak sense of self and depend on alcohol as a means to resolve conflicts. In fact, COAs are 3-5 times more likely to become alcoholics than children raised in nonalcoholic families (Jang, 1992).

The problems mentioned above call for urgent actions to conduct researches or find treatments for COAs. But in spite of the fact that numerous studies have been conducted to explore the characteristics of COAs, not many professional-level interventions and treatments have been developed in reality (Choi, 2002).

In that regard, the primary subjects of intervention in this study were COAs, especially those in their childhood. 
In comparison to children of nonalcoholic families, COAs experience a broader range of psychological difficulties such as anxiety, depression, low self-esteem, shame, and anger. But because familial disfunctionalities discourage self-expression, these negative emotions are not expressed but repressed instead. Therefore, this study sought to employ sandplay therapy to COAs, who fear that the problem of family alcoholism will be revealed to others.

Individual sandplay therapy helps us to express our thoughts and feelings in a free and protected space - i.e., the sandtray - through a trust-based relationship with a therapist, the formation of which is quite challenging in a group setting. Through the symbolic use of figures and the world created in the sandtray, we can express our thoughts and confront our inner pains, and feel safe while doing so because we would not have to reveal the problem in a direct, explicit manner (Kim, 2005). Thus sandplay therapy is likely an effective method of treatment for COAs, who may feel a psychological resistance to other types of treatment.

The purpose of this study was to see whether sandplay therapy can help COAs reduce their internalized shame and improve self-expression. In order to achieve this goal, the study addressed two research questions.

\section{B. Research Questions}

By employing sandplay therapy for COAs, this study sought to answer the following questions:

1. Can sandplay therapy help reduce internalized shame for children of alcoholics?

2. Can sandplay therapy help improve self-expression for children of alcoholics?

\section{Research Method}

\section{Participants}

\section{1) Recruitment and selection processes}

Participants of this research were COAs who attended two different local children's centers located in the city of $\mathrm{C}$ in South Chungcheong province. Recruitment was done by posting notifications that specified the purpose, effect, duration and location of the program for 
Journal of Symbols \& Sandplay Therapy, Vol.8 No.1.

a period of three weeks. By administering the Korean version of the Children of Alcoholics Screening Test (CAST-K) to those who volunteered, children who scored 13 or more out of 30 points were selected. Among them, those who agreed to participate in the program and also wished to receive counseling were assigned to experimental groups, and those who agreed to participate in the program but did not wish to receive counseling were assigned to the control group. There were a total of 30 participants, 15 in the experimental group and 15 in the control group.

\section{2) General characteristics of the participants}

The general characteristics of both children and adult participants of the experimental group and the control group are outlined in Table 3-1. Both groups were comprised of 9 boys (60.0\%) and 6 girls (40.0\%). There were two children aged 10 (13.3\%), six aged 11 (40.0\%), five aged $12(33.3 \%)$ and two aged $13(20.0 \%)$ in the experimental group, whereas there were three aged 10 (20.0\%), five aged $11(33.3 \%)$, five aged $12(333.3 \%)$ and two aged 13 (13.3\%) in the control group. The birth order of the two groups is as follows: two only childs (13.3\%), seven first childs (46.7\%), five second childs (33.3\%) and one third childs (6.7\%) in the experimental group, and four only childs (26.7\%), four first childs (26.7\%), six second childs $(40.0 \%)$ and one third child $(6.7 \%)$ in the control group. In terms of school grades, the experimental group had 9 children in the fair bracket (60.0\%) and 6 in the poor bracket (40.0\%), whereas the control group had 1 child in the good bracket (6.7\%), 9 in fair $(60.0 \%)$ and 5 in poor (33.3\%). As for the family form, 13 children (86.7\%) in the experimental group and $12(80.0 \%)$ from the control group lived with both parents, whereas $2(13.3 \%)$ in the experimental group and $3(20.0 \%)$ in the control group came from a single-parent household. The study also took in consideration the parents' highest completed level of education. In the experimental group, there were 7 fathers who graduated from high school (46.7\%) and 8 from college (53.3\%). In the control group, there were 1 father who graduated from middle school (6.7\%), 7 from high school (46.7\%), and 7 from college (46.7\%). As for the mothers, there were 9 who graduated from high school $(60.0 \%)$ and 6 from college $(40.0 \%)$ in the experimental group, and 1 from middle school (6.7\%), 7 from high school (46.7\%) and 7 from college $(46.7 \%)$ in the control group. 
No significant differences between children of the experimental group and the control group were observed in terms of their gender, age, birth order, academic grade, family form, and the parent's highest completed level of education, indicating that the two groups were homogenous.

Table 3-1. Characteristics of research participants

\begin{tabular}{|c|c|c|c|c|}
\hline & & $\begin{array}{l}\text { Experimental } \\
\text { group } \\
(n=15)\end{array}$ & $\begin{array}{l}\text { Control group } \\
\qquad(\mathrm{n}=15)\end{array}$ & $x^{2}$ \\
\hline & & $(\%)$ & $(\%)$ & \\
\hline \multirow{2}{*}{ Gender } & Male & $9(60.0)$ & $9(60.0)$ & \multirow{2}{*}{.000} \\
\hline & Female & $6(40.0)$ & $6(40.0)$ & \\
\hline \multirow{4}{*}{ Child's age } & 10 & $2(13.3)$ & $3(20.0)$ & \multirow{4}{*}{.29} \\
\hline & 11 & $6(40.0)$ & $5(33.3)$ & \\
\hline & 12 & $5(33.3)$ & $5(33.3)$ & \\
\hline & 13 & $2(13.3)$ & $2(13.3)$ & \\
\hline \multirow{4}{*}{ Child's birth order } & Only child & $2(13.3)$ & $4(26.7)$ & \multirow{4}{*}{1.58} \\
\hline & First & $7(46.7)$ & $4(26.7)$ & \\
\hline & Second & $5(33.3)$ & $6(40.0)$ & \\
\hline & Third & $1(6.7)$ & $1(6.7)$ & \\
\hline \multirow{3}{*}{ Child's academic grade } & Good & $0(.0)$ & $1(6.7)$ & \multirow{3}{*}{1.09} \\
\hline & Fair & $9(60.0)$ & $9(60.0)$ & \\
\hline & Poor & $6(40.0)$ & $5(33.3)$ & \\
\hline \multirow{3}{*}{ Family form } & Nuclear & $13(86.7)$ & $12(80.0)$ & \multirow{3}{*}{.37} \\
\hline & Single parent mother & $1(6.7)$ & $2(13.3)$ & \\
\hline & Single parent father & $1(6.7)$ & $1(6.7)$ & \\
\hline \multirow{3}{*}{$\begin{array}{c}\text { Father's highest completed } \\
\text { level of education }\end{array}$} & Middle school & $0(.0)$ & $1(6.7)$ & \multirow{3}{*}{1.07} \\
\hline & High school & $7(46.7)$ & $7(46.7)$ & \\
\hline & University & $8(53.3)$ & $7(46.7)$ & \\
\hline \multirow{3}{*}{$\begin{array}{l}\text { Mother's highest completed } \\
\text { level of education }\end{array}$} & Middle school & $0(.0)$ & $1(6.7)$ & \multirow{3}{*}{1.32} \\
\hline & High school & $9(60.0)$ & $7(46.7)$ & \\
\hline & University & $6(40.0)$ & $7(46.7)$ & \\
\hline
\end{tabular}


Journal of Symbols \& Sandplay Therapy, Vol.8 No.1.

2. Tools

1) The Korean Version of the Children of Alcoholics Screening Test (CAST-K)

Originally developed by John W. Jones (1981) and supplemented by Mi-rye Kim, Hwan-il Jang and Kyeong-bin Kim (1995), the Korean Version of the Children of Alcoholics Screening Test, or the CAST-K, is a 30 -item, self-report questionnaire developed to identify children who are either living with or have lived with alcoholic parents by assessing the children's perception, experiences and response related to a parent's alcohol use.

These items ask children questions related to their experience of psychological distress related to parental drinking, recognition of family troubles over parental drinking, efforts to encourage the parent to quit drinking, attempts to run away, exposure to domestic violence, belief that the parent is an alcoholic, and the wish to receive professional counseling. Response options for all items are "yes" or "no." The scores range from 0 to 30 , with one point for each "yes" answer. A total score of 13 or more indicates that the respondent is a child of an alcoholic.

The CAST-K scores indicated that there is no significant difference between the experimental group $(M=14.13)$ and the control group $(M=14.07)$, as shown in Table 3-2. In other words, the CAST-K level was homogeneous between both groups.

\section{2) Internalized Shame Scale (ISS)}

This study administered the Internalized Shame Scale (ISS), created by D. R. Cook (1987) and validated by Insook Lee and Haerim Choi (2005). It is comprised of 24 questions measuring shame and 6 questions measuring self-esteem. After analyzing Cook's ISS, Lee and

Table 3-2. CAST-K score: a comparison between the experimental group and the control group

\begin{tabular}{|c|c|c|c|}
\hline & $\begin{array}{l}\text { Experimental group } \\
\qquad(n=15)\end{array}$ & $\begin{array}{c}\text { Control group } \\
\qquad(n=15)\end{array}$ & $t$ \\
\hline & $\mathrm{M}(\mathrm{SD})$ & $\mathrm{M}(\mathrm{SD})$ & \\
\hline CAST-K score & $14.13(.92)$ & $14.07(.59)$ & -.24 \\
\hline
\end{tabular}


Choi discovered that the questions can be divided largely into four domains: inadequacy, emptiness, self-punishment and fear of mistake.

The inadequacy domain includes the situation in which we underestimate our own abilities and feels lonely by the belief that we are disregarded by others. The emptiness domain indicates the feeling of being empty internally as well as the feeling of losing the control over one's body and emotions. The self-punishment domain is characterized by tendencies to feel insufficient while striving for perfection, ruminate on painful events, want to erase our presence when exposed too much to others, and attack ourselves when making a mistake. The fear of mistake domain means that we are afraid to have our flaws exposed and to be judged by others.

The ISS is rated on a scale of 0 to 4 , with 0 points for "not at all" and 4 points for "almost always." The shame score is calculated by adding 24 items, excluding the ones on self-esteem. Cronbach's alpha as reported in the study of Cook was .96 for the clinical group, .95 for the non-clinical group, and .84 for test-retest reliability. In the study of Lee and Choi, the internal consistency was .93 .

The internal consistency or the Cronbach's alpha in this study was .87 , which is outlined together with the structure of the scale in Table 3-3.

Table 3-3. Structure and internal consistency of the Internalized Shame Scale

\begin{tabular}{cccc}
\hline & Number of items & Item number & Cronbach's a \\
\hline Inadequacy & 10 & $1,2,3,5,7,8,10,11,12,24$ & .81 \\
Emptiness & 5 & $23,26,27,29,30$ & .74 \\
Self-punishment & 5 & $15,17,20,22,25$ & .55 \\
Fear of mistake & 4 & $6,13,16,19$ & .62 \\
\hline Total & 24 & & .87 \\
\hline
\end{tabular}

\section{3) Self-Expressive Behavior Scale}

Created by Sung-hoe Kim in 1990, the Self-Expressive Behavior Scale has 100 items scored on a 5-poin Likert scale. It is comprised of four subscales: behavioral self-expression scale (25 items), cognitive self-expression scale (25 items), emotional self-expression scale (25 items) 
Journal of Symbols \& Sandplay Therapy, Vol.8 No.1.

and overall self-expression scale ( 25 items). The questions are a combination of affirmative and negative statements.

The behavioral self-expression scale includes questions related to measuring the subjects' level of knowing how to express themselves. The cognitive self-expression scale measures the level of irrational thinking that interrupts self-expressive behaviors. Questions of the emotional self-expression scale measure the level of anxiety that impedes self-expressive behaviors. The overall self-expression scale measures the overall level of self-expressive behaviors. Relatively higher scores in the behavioral, cognitive and emotional self-expression scales indicate that there were less influences of behavioral, cognitive and emotional reasons for non-self expressive behaviors. On the other hand, a relatively higher score in the overall self-expression scale signifies the ability to express oneself well.

The scores were calculated based on the method suggested in the paper of Kim (1990). First, the 100 items were divided into four subscales, with 25 items in each subscale. Then the items were again divided into affirmative statements and negative statements. In case of affirmative statements, the scores are: "almost never" $=1$, "generally never" $=2$, "half of the time" $=3$, "generally always" $=4$, "almost always" $=5$. It is the exact opposite for negative statements, where "almost always" $=1$, "generally always" $=2$, "half of the time" $=3$, "generally never" $=4$, and "almost never" $=5$. Then the total score is calculated by adding the scores of all four subscales. The internal consistency or the Cronbach's alpha in this study was .96, which is outlined together with the structure of the scale in Table 3-4.

Table 3-4. Structure and internal consistency of the Self-Expressive Behavior Scale

\begin{tabular}{cccc}
\hline Subscales & Number of Items & Item number & Cronbach's a \\
\hline Behavioral self-expression & 25 & $1-25$ & .90 \\
Cognitive self-expression & 25 & $26-50$ & .88 \\
Emotional self-expression & 25 & $51-75$ & .85 \\
Overall self-expression & 25 & $56-100$ & .90 \\
\hline Total & 100 & & .96 \\
\hline
\end{tabular}




\section{Research Procedure}

\section{1) Pretest}

Before going ahead with the sandplay therapy program, CAST-K, the ISS and Self-Expressive Behavior Scale were administered to both the experimental group and the control group so as to obtain their pretest scores.

\section{2) Sandplay therapy}

A 45-minute, weekly sandplay session was provided to the experimental group for a total of 12 sessions, from November 2012 to March 2013. The sessions were held by two different sandplay therapists. Prior to therapy, the participants filled out a consent form agreeing to have their sessions videotaped and their pictures photographed. Any noteworthy behaviors and stories made by the participants during the creation of a sandpicture were recorded on a notebook by the therapists.

The decision that 12 sessions would be given to the participants is based on the studies of Jang (2010) and Oh (2011), in which 12 sessions of sandplay therapy proved to be effective. Further therapy was provided to those who wished to continue.

\section{3) Posttest}

After sandplay therapy was finished, the ISS and Self-Expressive Behavior Scale were again administered to both the experimental group and the control group.

\section{4) Data Processing}

Collected data was analyzed using the SPSS 18.0. First, to compare the general characteristics of the experimental group and the control group, frequency and percentage were calculated after which the chi-square test was conducted. Next, analysis of covariance (ANCOVA) was administered while controlling the pretest scores as covariates in order to see the effect of sandplay therapy on the internalized shame and self-expression in COAs. 
Journal of Symbols \& Sandplay Therapy, Vol.8 No.1.

\section{Result and interpretation}

\section{Confirmation of the Research Questions}

1) The effect of sandplay therapy in reducing internalized shame in COAs

To answer research question 1 which asks whether sandplay therapy can reduce internalized shame in COAs, pretest and posttest scores of both groups were compared and ANCOVA was conducted. The results are specified in Table 4-1 and Table 4-2:

In the inadequacy domain, the experimental group's posttest score $\quad(M=16.73$, $\mathrm{SD}=6.13)$ was lower than the pretest score $(\mathrm{M}=23.20, \mathrm{SD}=6.62)$. The control group, in contrast, showed almost no difference between the pretest score $(\mathrm{M}=21.00, \mathrm{SD}=5.40)$ and posttest score $(\mathrm{M}=21.47, \mathrm{SD}=4.22)$. The study used ANCOVA to compare the posttest means of the two groups, controlling the pretest inadequacy scores of both groups as the covariate. As exhibited in Table 4-2, there was a statistically significant difference between the two groups (F $=77.98, \mathrm{p}<.001)$. It can therefore be said that sandplay therapy reduced inadequacy in COAs.

Table 4-1. Mean score and standard deviation for internalized shame

\begin{tabular}{ccccc}
\hline & & & Pretest & Posttest \\
\cline { 5 - 5 } Inadequacy & & $\mathrm{n}$ & $\mathrm{M}(\mathrm{SD})$ & $\mathrm{M}(\mathrm{SD})$ \\
\hline \multirow{2}{*}{ Emptiness } & Control group & 15 & $21.00(5.40)$ & $16.73(6.13)$ \\
& Experimental group & 15 & $9.07(4.17)$ & $6.33(3.62)$ \\
\hline \multirow{2}{*}{ Self-punishment } & Control group & 15 & $9.00(3.14)$ & $9.33(3.22)$ \\
\hline \multirow{2}{*}{ Fear of mistake } & Experimental group & 15 & $9.93(3.47)$ & $7.00(2.83)$ \\
& Control group & 15 & $9.07(2.71)$ & $9.00(2.33)$ \\
\hline \multirow{2}{*}{ Total score } & Experimental group & 15 & $11.73(1.98)$ & $9.33(2.69)$ \\
& Control group & 15 & $10.87(1.73)$ & $10.53(1.85)$ \\
\hline
\end{tabular}


$\mathrm{Na}$, Gyoung hee - Mikyung Jang / The Effects of Sandplay Therapy on Internalized Shame and Self-expression of Children of Alcoholics

Table 4-2. ANCOVA between groups for internalized shame

\begin{tabular}{|c|c|c|c|c|c|}
\hline & Source & Sum of squares & $d f$ & Mean squares & $F$ \\
\hline & Covariate (pretest) & 670.24 & 1 & 670.24 & $170.04^{* * *}$ \\
\hline & Between groups & 307.39 & 1 & 307.39 & $77.98^{* * *}$ \\
\hline \multirow[t]{5}{*}{ Inadequacy } & Error & 106.43 & 27 & 3.94 & \\
\hline & Total & 11889.00 & 30 & & \\
\hline & Corrected total & 944.70 & 29 & & \\
\hline & Covariate (pretest) & 290.52 & 1 & 290.52 & $205.60^{* * *}$ \\
\hline & Between groups & 70.14 & 1 & 70.14 & $49.64^{* * *}$ \\
\hline \multirow[t]{5}{*}{ Emptiness } & Error & 38.15 & 27 & 1.41 & \\
\hline & Total & 2237.00 & 30 & & \\
\hline & Corrected total & 396.17 & 29 & & \\
\hline & Covariate (pretest) & 159.14 & 1 & 159.14 & $148.86^{* * *}$ \\
\hline & Between groups & 52.11 & 1 & 52.11 & $48.75^{* * *}$ \\
\hline \multirow[t]{5}{*}{ Self-punishment } & Error & 28.86 & 27 & 1.07 & \\
\hline & Total & 2138.00 & 30 & & \\
\hline & Corrected total & 218.00 & 29 & & \\
\hline & Covariate (pretest) & 37.74 & 1 & 37.74 & $9.15^{* *}$ \\
\hline & Between groups & 21.49 & 1 & 21.49 & $5.21^{*}$ \\
\hline \multirow[t]{5}{*}{ Fear of mistake } & Error & 111.33 & 27 & 4.12 & \\
\hline & Total & 3120.00 & 30 & & \\
\hline & Corrected total & 159.87 & 29 & & \\
\hline & Covariate (pretest) & 2581.04 & 1 & 2581.04 & $250.77^{* * * *}$ \\
\hline & Between groups & 1503.85 & 1 & 1503.85 & $146.11^{* * *}$ \\
\hline \multirow[t]{3}{*}{ Total score } & Error & 277.89 & 27 & 10.29 & \\
\hline & Total & 64146.00 & 30 & & \\
\hline & Corrected total & 3755.47 & 29 & & \\
\hline
\end{tabular}

${ }^{*} p<.05,{ }^{* *} p<.01,{ }^{* * *} p<.001$

In the emptiness domain, the posttest score $(\mathrm{M}=6.33, \mathrm{SD}=3.62)$ of the experimental group was lower than the pretest score $(\mathrm{M}=9.07, \mathrm{SD}=4.17)$. However, hardly any changes 
Journal of Symbols \& Sandplay Therapy, Vol.8 No.1.

were observed between the pretest score $(M=9.00, S D=3.14)$ and the posttest score $(M=9.33$, $\mathrm{SD}=3.22$ ) of the control group. With the pretest emptiness scores of both groups as covariates, ANCOVA was conducted on the posttest scores, and a statistically significant difference was observed between the two groups $(\mathrm{F}=49.64, \mathrm{p}<.001)$, as can be seen in Table 4-2. Therefore, it can be said that sandplay therapy reduced the feeling of emptiness in COAs.

In the self-punishment domain, the posttest score $(\mathrm{M}=7.00, \quad \mathrm{SD}=2.83)$ of the experimental group was lower than the pretest score $(\mathrm{M}=9.93, \mathrm{SD}=3.47)$. On the contrary, hardly any changes were observed between the pretest score $(M=9.07, \quad S D=2.71)$ and the posttest score $(\mathrm{M}=9.00, \mathrm{SD}=2.33)$ of the control group. ANCOVA showed a statistically significant difference between the two groups $(\mathrm{F}=48.75, \mathrm{p}<.001)$. Therefore, it can be said that sandplay therapy reduced the feeling of self-punishment in COAs.

In the fear of mistake domain, the posttest score $(\mathrm{M}=9.33, \mathrm{SD}=2.69)$ of the experimental group was lower than the pretest score $(\mathrm{M}=11.73, \mathrm{SD}=1.98)$. But almost no changes were observed between the pretest score $(\mathrm{M}=10.87, \mathrm{SD}=1.73)$ and the posttest score $(\mathrm{M}=10.53, \mathrm{SD}=1.85)$ of the control group. ANCOVA showed a statistically significant between groups difference $(\mathrm{F}=5.21, \mathrm{p}<.05)$, from which it can be said that sandplay therapy reduced the dear of mistake in COAs.

In terms of the total score, the posttest score $(\mathrm{M}=39.40, \mathrm{SD}=11.93)$ of the experimental group was lower than the pretest score $(M=53.93, S D=12.13)$, whereas there were hardly any changes between the pretest score $(M=49.93, S D=9.87)$ and the posttest score $(M=50.33, S D=7.87)$ of the control group. ANCOVA showed a statistically significant between groups difference $(\mathrm{F}=146.11, \mathrm{p}<.05)$.

In sum, sandplay therapy was effective in reducing internalized shame-that is, inadequacy, emptiness, self-punishment, and fear of mistake-in COAs.

\section{2) The effect of sandplay therapy in improving self-expression in COAs}

To answer research question 2 which asks whether sandplay therapy can promote self-expression in COAs, pretest and posttest scores of both groups were compared and ANCOVA was conducted. The results are specified in Table 4-3 and Table 4-4: 
Table 4-3. Posttest changes in self-expression

\begin{tabular}{ccccc}
\hline & & & Pretest & Posttest \\
\cline { 5 - 5 } & & $\mathrm{n}$ & $\mathrm{M}(\mathrm{SD})$ & $\mathrm{M}(\mathrm{SD})$ \\
\hline $\begin{array}{c}\text { Behavioral } \\
\text { self-expression }\end{array}$ & Experimental group & 15 & $62.00(12.02)$ & $80.47(14.72)$ \\
\hline $\begin{array}{c}\text { Cognitive } \\
\text { self-expression }\end{array}$ & Experimental group & 15 & $62.80(11.77)$ & $78.00(12.15)$ \\
\hline Emotional & Control group & 15 & $63.87(10.87)$ & $62.00(10.06)$ \\
self-expression & Experimental group & 15 & $66.53(10.21)$ & $78.27(11.99)$ \\
\hline Overall & Control group & 15 & $66.33(8.95)$ & $66.73(8.88)$ \\
self-expression & Experimental group & 15 & $64.33(12.52)$ & $80.33(15.41)$ \\
\hline Total & Control group & 15 & $67.13(11.72)$ & $68.07(10.54)$ \\
\hline & Experimental group & 15 & $255.67(40.04)$ & $317.07(48.78)$ \\
\hline
\end{tabular}

In the behavioral self-expression domain, the experimental group's posttest score $(\mathrm{M}=80.47, \mathrm{SD}=14.72)$ was higher than the pretest score $(\mathrm{M}=62.00, \mathrm{SD}=12.02)$. Similarly, the control group's posttest score $(\mathrm{M}=65.13, \mathrm{SD}=10.47)$ was higher than the pretest score $(\mathrm{M}$ $=64.80, \mathrm{SD}=11.21)$. The study used ANCOVA to compare the posttest means of the two groups, controlling the pretest behavioral self-expression scores as covariates. As exhibited in Table 4-4, there was a statistically significant difference between the two groups $(F=40.97, p$ $<$.001). It can therefore be said that sandplay therapy promoted behavioral self-expression in COAs.

In the cognitive self-expression domain, the experimental group's posttest score $(\mathrm{M}=78.00, \mathrm{SD}=12.15)$ was higher than the pretest score $(\mathrm{M}=62.80, \mathrm{SD}=11.77)$. In contrast, the control group's posttest score $(\mathrm{M}=62.00, \mathrm{SD}=10.06)$ was lower than its pretest score $(\mathrm{M}=63.87, \mathrm{SD}=10.87)$. With the pretest cognitive self-expression scores of both groups as covariates, ANCOVA was conducted on the posttest scores, and a statistically significant difference was observed between the two groups $(\mathrm{F}=74.94, \mathrm{p}<.001)$. Therefore, it can be said that sandplay therapy promoted cognitive self-expression in COAs.

In the emotional self-expression domain, the experimental group's posttest score 
Journal of Symbols \& Sandplay Therapy, Vol.8 No.1.

Table 4-4. ANCOVA between groups for interpersonal stress

\begin{tabular}{|c|c|c|c|c|c|}
\hline & Source & Sum of squares & $d f$ & mean squares & $F$ \\
\hline \multirow{5}{*}{$\begin{array}{c}\text { Behavioral } \\
\text { self-expression }\end{array}$} & Covariate (pretest) & 3019.15 & 1 & 3019.15 & $52.65^{* * *}$ \\
\hline & Between groups & 2349.27 & 1 & 2349.27 & $40.97^{* * *}$ \\
\hline & Error & 1548.32 & 27 & 57.35 & \\
\hline & Total & 165326.00 & 30 & & \\
\hline & Corrected total & 6330.80 & 29 & & \\
\hline \multirow{5}{*}{$\begin{array}{c}\text { Cognitive } \\
\text { self-expression }\end{array}$} & Covariate (pretest) & 2713.62 & 1 & 2713.62 & $94.86^{* * *}$ \\
\hline & Between groups & 2143.80 & 1 & 2143.80 & $74.94^{* * *}$ \\
\hline & Error & 772.38 & 27 & 28.61 & \\
\hline & Total & 152406.00 & 30 & & \\
\hline & Corrected total & 5406.00 & 29 & & \\
\hline \multirow{5}{*}{$\begin{array}{c}\text { Emotional } \\
\text { self-expression }\end{array}$} & Covariate (pretest) & 2259.99 & 1 & 2259.99 & $71.13^{* * *}$ \\
\hline & Between groups & 965.41 & 1 & 965.41 & $30.38^{* * *}$ \\
\hline & Error & 857.87 & 27 & 31.77 & \\
\hline & Total & 161803.00 & 30 & & \\
\hline & Corrected total & 4115.50 & 29 & & \\
\hline \multirow{5}{*}{$\begin{array}{c}\text { Overall } \\
\text { self-expression }\end{array}$} & Covariate (pretest) & 4025.84 & 1 & 4025.84 & 127.52 \\
\hline & Between groups & 1671.62 & 1 & 1671.62 & $52.95^{* * *}$ \\
\hline & Error & 852.42 & 27 & 31.57 & \\
\hline & Total & 171176.00 & 30 & & \\
\hline & Corrected total & 6006.80 & 29 & & \\
\hline \multirow{5}{*}{ Total } & Covariate (pretest) & 36480.22 & 1 & 36480.22 & $95.54^{* * *}$ \\
\hline & Between groups & 28233.64 & 1 & 28233.64 & $73.94^{* * *}$ \\
\hline & Error & 10309.65 & 27 & 381.84 & \\
\hline & Total & 2583895.00 & 30 & & \\
\hline & Corrected total & 69587.50 & 29 & & \\
\hline
\end{tabular}

${ }_{* * * *} p<.001$

$(\mathrm{M}=78.27, \mathrm{SD}=11.99)$ was higher than its pretest score $(\mathrm{M}=66.53, \mathrm{SD}=10.21)$. Similarly, the control group's posttest score $(\mathrm{M}=66.73, \mathrm{SD}=8.88)$ was slightly higher than its pretest score $(\mathrm{M}=66.33, \mathrm{SD}=8.93)$. As shown in Table 4-4, ANCOVA indicated a statistically significant 
difference between the two groups $(\mathrm{F}=30.38, \mathrm{p}<.001)$. Therefore, it can be said that sandplay therapy promoted emotional self-expression in COAs.

In the overall self-expression domain, the experimental group's posttest score $(\mathrm{M}=80.33, \mathrm{SD}=15.41)$ was higher than its pretest score $(\mathrm{M}=64.33, \mathrm{SD}=12.52)$. Similarly, the control group's posttest score $(\mathrm{M}=68.07, \mathrm{SD}=10.54)$ was slightly higher than its pretest score $(\mathrm{M}=67.13, \mathrm{SD}=11.72)$. ANCOVA showed a statistically significant between groups difference $(\mathrm{F}=30.38, \mathrm{p}<.001)$, from which it can be said that sandplay therapy promoted overall self-expression in COAs.

In terms of the total score, the experimental group's posttest score $(M=317.07$, $\mathrm{SD}=48.78)$ was higher than its pretest score $(\mathrm{M}=255.67, \mathrm{SD}=40.04)$. On the other hand, hardly any changes were observed between the pretest score $(M=262.13, S D=31.40)$ and the posttest score $(\mathrm{M}=261.93, \mathrm{SD}=31.03)$ of the control group. ANCOVA showed a statistically significant between groups difference $(\mathrm{F}=73.94, \mathrm{p}<.001)$.

In sum, sandplay therapy was effective in promoting self-expression-that is, behavioral self-expression, cognitive self-expression, emotional self-expression, overall self-expression-in COAs.

\section{Conclusion and Discussions}

\section{Summary and Discussions}

The purpose of this study was to analyze the effect of sandplay therapy on children of alcoholic, or COAs. More specifically, it sought to examine whether sandplay therapy helps reduce internalized shame and promote self-expression in COAs.

Using SPSS 18.0 statistical program, the collected data was analyzed as follows: First, to compare the general characteristics of children in the experimental group and the control group, frequency and percentage were calculated and then the chi-squared test was performed. Second, ANCOVA was performed on the posttest results, with the pretest results controlled as covariance, in order to see the effect of sandplay therapy on internalized shame and self-expression in COAs. The results were further verified by setting the significance level to a 
Journal of Symbols \& Sandplay Therapy, Vol.8 No.1.

$=0.05$.

The results of this study were as follows: First, there was a statistically significant difference between the pretest score and the posttest score in the ISS, which was administered in the effort to answer the first research question: that is, whether sandplay therapy can reduce internalized shame in COAs. In other words, sandplay therapy proved to be effective in reducing internalized shame-such as inadequacy, emptiness, self-punishment, and fear of mistake-in COAs. This result supports the study of Jeon (2006), which found that sandplay therapy serves as an opportunity to express anxiety and repressed psychology by allowing clients to express freely their inner problems.

Second, there was a statistically significant difference between the pretest score and the posttest score in the Self-Expressive Behavior Scale, which was administered in the effort to answer the second research question: that is, whether sandplay therapy can promote self-expression in COAs. In other words, sandplay therapy proved to be effective in promoting different types of self-expression-such as behavioral self-expression, cognitive self-expression, emotional self-expression and overall self-expression-in COAs. Such finding is in sync with the study of Noh and Hwang (1998), which argued that the containing and empathetic functions of a sandplay therapist enable clients to express freely their thoughts and emotions, provide an opportunity to reconstitute an image of themselves in a positive manner, and facilitate growth. It is also aligned with the findings of Lee (2009), Jeon (2006) and Lee (2001) that sandplay therapy positively influences the ability of self-expression by allowing clients to express their thoughts and emotions. It is further in support of the study of Kim (2011) which observed that sandplay therapy promotes self-expression in female immigrants by marriage

Despite an urgent need for further studies and treatments for COAs, there is a lack of dedicated programs for these children. Most of related studies or interventions are done on the sidelines of the programs for alcoholic parents. In addition, interventions are mostly made in the form of group counseling, the effect of which is not clearly demonstrated in reality. What sets this study apart from existing studies is that it selected COAs as the primary subject of intervention, and allowed trust-building with the therapist-which is difficult in a group setting-through individual sandplay therapy. At the time when this study was conducted, 
there was a lack of case studies on the effectiveness of sandplay therapy for COAs. Against this backdrop, this study serves as a basic material for validating the effect of sandplay therapy. Hopefully, this study will pave the way for further related studies in the future.

\section{Limitations and Suggestions}

Suggestions for future research efforts based on the limitations of this study are as follows: The first limitation faced by this study was the selection of the participants. Because people are often reluctant to admit publically that their family has an alcoholism issue, not many were willing to take part. Therefore, participants were constrained to 30 children from local child welfare centers located in a single city, making it difficult to generalize the findings. In that regard, future studies need to recruit a larger number of participants from a range of regions so as to make sure that the results can be generalized.

Second, the participants were limited to children aged 10 to 13 . There is a need to conduct a study on COAs from various age groups.

Nevertheless, this study is meaningful because it validated the effectiveness of sandplay therapy as a therapeutic approach for COAs, while there is only a small number of existing related studies. Sandplay therapy's positive impact on internalized shame and self-expression in COAs is attributable to its power to help these children express their repressed negative emotions in safe manner by providing a free and protected space and also the formation of a trust relationship with the therapist, which is difficult to achieve in a group therapy setting. Hopefully, the results of this study will trigger further researches dealing with the topic of COAs, exploring a range of methods in treating the children's psychology and inner emotions.

\section{References}

Choi, S. (1996). Study on the elements influencing the drinking behaviors of the alcoholics' children. Master's thesis, Ewha Woman's University.

Choi, S. (2002). Four characteristics of COAs and different intervention methods. A Collection of 
Journal of Symbols \& Sandplay Therapy, Vol.8 No.1.

Dissertations, Pyeongtaek University, 16, 93-116.

Cook, D. R. (1987). Measuring shame: The internalized shame scale. Alcoholism Treatment Quarterly, 4, 197-215.

Hwang, H. (1998). Effect of parental drinking on children of alcoholic parents: Mainly on the characteristics of children of alcoholic parents. Master's thesis, Kyung Hee University.

Jang, S. (1992). A study on the effect of short-term group therapy program for promoting self-esteem in children of alcoholics. Master's thesis, Ewha Woman's University.

Jeon, B. (2006). The effect of self-expression through sandplay therapy on the self-esteem and interpersonal relationships of adolescents. Master's thesis, Hallym University.

Kim, K. (2005). Sandtray play therapy: Symbols and fantasies. Seoul: Yangseowon Publishing Group.

Lee, I., \& Choi, H. (2005). Assessment of shame and its relationship with maternal attachment, hypersensitive narcissism and loneliness. Korean Journal of Psychology, 17(3), 651-670.

Lee, J. (1995). A study on the mental health of children of alcoholics. Master's thesis, Soongsil University.

Min, E. (2000). The impact of father's problematic drinking on the adaptation of adolescent children. Master's thesis, Pusan University.

Noh, C., \& Hwang, Y. (1998). Sandplay therapy: Experiences and expressions. Seoul: Dongseo Cultural Center

Park, H., Lee, S., \& Jeh, G. (2001). Development of a tool for assessing psychosocial characteristics in adult children of alcoholics. Korea Drinking Culture and Alcohol Research.

Sohn, Y. (1993). Characteristics of adolescent children of alcoholics. Master's thesis, Yonsei University.

Workman, M., \& Beer, J. (1992). Depression, suicide ideation, and aggression among high school students whose parents are divorced and use alcohol at home. Psychological Reports, $70,503-511$ 